\title{
Electron impact excitation of methane: determination of appearance energies for dissociation products
}

\author{
M Danko ${ }^{1}$, J Orszagh ${ }^{1}$, M Ďurian ${ }^{1}$, J Kočišek ${ }^{1}$, M Daxner $^{2}$, S Zöttl ${ }^{2}$, \\ J B Maljković ${ }^{3}$, J Fedor ${ }^{4}$, P Scheier ${ }^{2}$, S Denifl ${ }^{2,5}$ and Š Matejčík ${ }^{1,5}$ \\ ${ }^{1}$ Department of Experimental Physics, Faculty of Mathematics, Physics and Informatics, \\ Comenius University, Mlynská dolina, 84248 Bratislava, Slovakia \\ 2 Institute for Ion Physics and Applied Physics, Association Euroatom ÖAW, University of Innsbruck, \\ Technikerstrasse 25, A-6020 Innsbruck, Austria \\ ${ }^{3}$ Laboratory for Atomic Collision Processes, Institute of Physics, University of Belgrade, \\ Pregrevica 118, 11080 Belgrade, Serbia \\ ${ }^{4}$ Department of Chemistry, University of Fribourg, Chemin du Musée 9, CH-1700 Fribourg, Switzerland \\ E-mail: matejcik@fmph.uniba.sk and Stephan.Denifl@uibk.ac.at
}

\begin{abstract}
In this work, we present an experimental study of dissociative excitation of $\mathrm{CH}_{4}$ utilizing a crossed electron molecular beam experiment. Methane was excited by nearly monochromatic electrons generated by a trochoidal electron monochromator. The dissociative products were identified on the basis of the emission spectra in the ultraviolet-visible (UV/VIS) spectral range. The excitation functions were recorded as the function of the electron energy for different emission bands of the fragments (Balmer series for $\mathrm{H}: n=3,4 \ldots 9 \rightarrow 2$, and moreover, CH: $\mathrm{A}^{2} \Delta \rightarrow \mathrm{X}^{2} \Pi, \mathrm{CH}: \mathrm{B}^{2} \Sigma^{-} \rightarrow \mathrm{X}^{2} \Pi, \mathrm{CH}: \mathrm{C}^{2} \Sigma^{+} \rightarrow \mathrm{X}^{2} \Pi, \mathrm{CH}^{+}: \mathrm{B}^{1} \Delta \rightarrow \mathrm{A}^{1} \Pi$, and CI: $2 \mathrm{p} 3 \mathrm{~s}^{1} \mathrm{P}^{\mathrm{o}} \rightarrow 2 \mathrm{p}^{2}{ }^{1} \mathrm{~S}_{0}$ ). From the experimental data we have determined the threshold energies for excitation of particular fragments. Present experimental results indicate that the threshold energies for some dissociative excitation channels could be lower by $\sim 1-2 \mathrm{eV}$ in comparison to earlier studies and indicate that different dissociative processes may be operative at the threshold than assumed in the former studies.
\end{abstract}

Online supplementary data available

\section{Introduction}

Collisions of electrons with methane play an important role in several areas of physics and chemistry [1]. This arises from the fact that methane is present in planetary atmospheres (like, for example, Earth, Jupiter or Titan) [2-7] as well as in the interstellar medium [8]. Moreover, it is also of relevance in the divertor region of thermonuclear fusion plasmas [9] and in technological low temperature plasmas [10]. Radiative and collisional processes in the plasma edge

\footnotetext{
${ }^{5}$ Authors to whom any correspondence should be addressed.
}

region play a considerable role for controlling the dynamics of a plasma and hence its stability. It needs to be kept in mind, however, that simple hydrocarbon molecules like methane are released by chemical erosion of the plasma vessel due to plasma-wall interactions. Although efforts are made to replace carbon-based composites with other materials like tungsten or beryllium, divertors still consist preferentially of carbon due to the high heat load [9]. Thus, data on electron-hydrocarbon collisions are required which are important factors for the simulations of the transport of impurities and their chemistry in the scrape-off layer plasma. It should be noted that for small hydrocarbons (including methane) collisional data have 
been compiled in the HYDKIN database [11, 12], which includes (dissociative) electron ionization cross sections, recombination cross sections as well as dissociative electron excitation cross sections.

Due to the broad field of applications for studies on methane an extended number of previous experimental investigations on electron ionization (see [13, 14]), electron attachment $[15,16]$ and dissociative electron impact excitation can be found in the literature for this molecule [17-20]. Emission spectra for electron projectiles [11-14] as well as for photo-excitation [21-23] were reported. In contrast to photo-excitation, electron impact implies also optically forbidden excited states and monitors their subsequent decay to lower states. Pang et al investigated electron impact emission cross sections for $\mathrm{CH}_{4}$ and $\mathrm{C}_{2} \mathrm{H}_{2}$ in the VUV region from 40 to $200 \mathrm{~nm}$ [17]. Three studies are most related to the present study since electrons were used as projectiles and fluorescence signals in the VIS/UV range were recorded. Aarts et al [18] reported absolute emission cross sections for Balmer $\mathrm{H}_{\beta}$ and $\mathrm{CH}\left(\mathrm{A}^{2} \Delta \rightarrow \mathrm{X}^{2} \Pi\right)$ radiation between $20 \mathrm{eV}$ and $5 \mathrm{keV}$. Moreover, they reported the threshold energies for these transitions and additionally for $\mathrm{H}_{\alpha}$ and $\mathrm{H}_{\gamma}$. Donohue et al [19] measured photon emission from fragments formed upon electron impact with methane, ethylene and methanol in the spectral range between $180 \mathrm{~nm}$ and $500 \mathrm{~nm}$. They reported a larger number of transitions compared to Aarts et al including fluorescence signal from ionic $\mathrm{CH}^{+}$and atomic carbon fragments and determined threshold values as well. A more recent fluorescence study on methane using electrons as projectiles was carried out by Motohashi et al [20] who determined absolute emission cross sections for several transitions of hydrogen (Lyman $\alpha-\varepsilon$ and Balmer $\alpha-\varepsilon$ series), $\mathrm{CH}\left(\mathrm{A}^{2} \Delta \rightarrow \mathrm{X}^{2} \Pi\right)$ and $\mathrm{C}\left(2 \mathrm{p} 3 \mathrm{~s} \rightarrow 2 \mathrm{p}^{2}\right.$ and $2 \mathrm{~s} 2 \mathrm{p}^{3} \rightarrow 2 \mathrm{~s}^{2} 2 \mathrm{p}^{2}$, respectively). They investigated the electron energy range from threshold up to $1 \mathrm{keV}$ and determined the appearance energies for some of the transitions mentioned. All references on electron impact of methane [17-20] investigated also the high energy range in which Fano plots reveal the optical activity of the investigated transition. It turned out that most fragments formed in electron impact excitation are formed from the ground state of $\mathrm{CH}_{4}$ via optically forbidden states. We note that very recently also coincidence techniques were used to measure the electron energy loss spectra of $80 \mathrm{eV}$ electrons in collisions with $\mathrm{CH}_{4}$ tagged with Lyman alpha emission [24, 25].

In the present study, we investigated dissociative electron excitation of methane utilizing a monochromatized electron beam (generated by a trochoidal electron monochromatorTEM) and a detection system to monitor the fluorescence of (electronically) excited species. We recorded the emission spectrum in the spectral region from 185 to $710 \mathrm{~nm}$ at the electron energy of $50 \mathrm{eV}$. Subsequently, we determined the electron energy dependence for the transitions observed and derived thresholds for the corresponding transitions. For the majority of the dissociative processes, we found that the present values of the threshold energies are considerably shifted to lower values compared to previous studies. For example, in the case of the Balmer transition $\mathrm{H}(3-2)$ the present value is found $1.6 \mathrm{eV}$ below the earlier onset [20]. We believe that the main reason for this observation is the improved sensitivity and high signal-to-noise ratio of the present experimental system in comparison to earlier systems, as well as improved resolution in the electron energy calibration due to utilization of the electron monochromator.

\section{Experimental details}

Electron impact excitation of methane $\left(\mathrm{CH}_{4}\right)$ was studied using a recently developed crossed beam apparatus in Bratislava [26]. A detailed schematic view of the apparatus is presented in figure 1 . In short, electrons thermally emitted from a commercial tungsten hairpin filament (Agar Scientic A054) were monochromatized using a trochoidal electron monochromator (TEM) [27] which employs a crossed electric and magnetic field in the dispersion region. A magnetic field of $5 \times 10^{-3} \mathrm{~T}$ was used, aligned in the direction of the electron beam. For the present measurements, due to relatively low cross sections for the processes studied, the electron energy resolution of the TEM was set to $300 \mathrm{meV}$ full width at half maximum (FWHM) in favour of a higher electron current (typically $\sim 750 \mathrm{nA}$ ). The resolution of the electron beam was determined using the retarding potential method [28]. The electron current was monitored during the experiment using picoamperemeter Keithley 6485 and the data were recorded as a function wavelength (in the case of optical spectra) or as a function of the acceleration voltage (in the case of the energy scans). The variations of the electron current during the measurements of the optical spectra were less than $5 \%$. In the case of electron energy scans the electron current as a function of the acceleration voltage was flat in the measured energy range with statistical fluctuations less than $10 \%$.

The electron beam was perpendicularly crossed with an effusive beam of $\mathrm{CH}_{4}$ molecules in the interaction zone of the TEM. The gas (from Linde Gas; purity of 99.98\%) was introduced by a capillary $(0.5 \mathrm{~mm}$ diameter and $10 \mathrm{~mm}$ length) connected to an external gas inlet by a leak valve. The absolute pressure inside the capillary was measured by a capacitive pressure gauge (Pfeiffer Vacuum CMR 362) and the pressure inside the capillary was kept constant during the experiments. The typical working pressure inside the vacuum chamber was $1 \times 10^{-4}$ mbar as measured by ionization gauge (Pfeiffer Vacuum PBR 260), which was switched off during the measurements. The background pressure of the vacuum system without gas introduction was better than $5 \times 10^{-8}$ mbar. The photons emitted from the excited species $\left(90^{\circ}\right.$ in reference to the electron and molecular beam and within the $26^{\circ}$ acceptance angle) were transferred by optical lens (biconvex, $f=51 \mathrm{~mm}$, UV fused silica) through an $\mathrm{MgF}_{2}$ vacuum window out of the vacuum and focused into the entrance of a Czerny-Turner optical monochromator (1/4 m, Cornerstone 260 , Newport, using $1200 / \mathrm{mm}$ grid in the first order) by additional lens (by plano-convex $f=150 \mathrm{~mm}$, UV fused silica). In order to increase the signal intensity we have used an additional spherical mirror with the focus in the centre of the interaction zone. We did not use any method to determine the polarization of the emitted light in this experiment. The width 


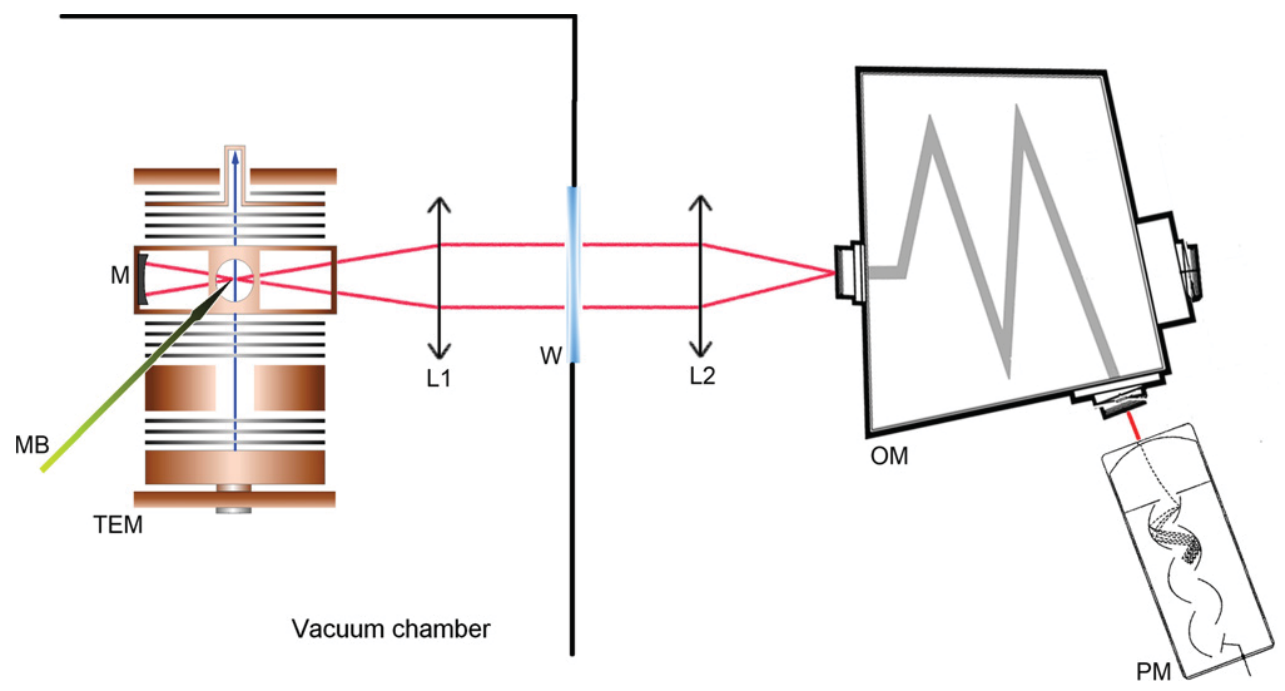

Figure 1. Schematic view of the experimental setup. TEM: trochoidal electron monochromator, MB: molecular beam, M: spherical mirror, L1, L2: fused silica lenses, $\mathrm{W}: \mathrm{MgF}_{2}$ window, OM: optical monochromator, PM: photomultiplier.

of the slit of the optical monochromator was set to $200 \mu \mathrm{m}$ in order to achieve optimum sensitivity with sustaining sufficient resolution (resolution of $0.8 \mathrm{~nm}$ FWHM as measured at $588 \mathrm{~nm}$ Ar line). Higher resolution spectra have been measured with a $70 \mu \mathrm{m}$ slit (resolution $0.3 \mathrm{~nm}$ FWHM as measured at the same line). The photons were detected by a Hamamatsu H4220P photomultiplier which was thermoelectrically cooled to $-25{ }^{\circ} \mathrm{C}$. The photomultiplier is sensitive in the spectral $\mathrm{UV} / \mathrm{VIS}$ region between 185 and $710 \mathrm{~nm}$.

In order to reduce the black-body radiation caused by the filament of the electron monochromator, the filament was located in specially designed electrodes and the surfaces of the electrodes and the inner walls of the vacuum system were covered with colloidal graphite. This considerably reduced the intensity of the background radiation so that in the present experiment the fluorescence signal was not superimposed by the background radiation from the hot filament.

We calibrated the electron energy scale by measuring the emission cross section of the $(0,0)$ band of the second positive system of $\mathrm{N}_{2}\left(\mathrm{C}^{3} \Pi_{\mathrm{u}} \rightarrow \mathrm{B}^{3} \Pi_{\mathrm{g}}\right)$ at $337 \mathrm{~nm}[26,29]$ and the He I $\left(1 \mathrm{~s} 2 \mathrm{p}^{3} \mathrm{P}^{\mathrm{o}}{ }_{1,2}-1 \mathrm{~s} 4 \mathrm{~d}^{3} \mathrm{D}_{1,2,3}\right) 447.14 \mathrm{~nm}$ emission line [30]. The $N_{2}\left(C^{3} \Pi_{u} \rightarrow B^{3} \Pi_{g}\right)(0,0)$ cross section exhibits a pronounced peak at $14.1 \mathrm{eV}$. The cross section for the He I $\left(1 \mathrm{~s} 2 \mathrm{p}^{3} \mathrm{P}^{\mathrm{o}}{ }_{1,2}-1 \mathrm{~s} 4 \mathrm{~d}^{3} \mathrm{D}_{1,2,3}\right)$ transition exhibits a step at $23.736 \mathrm{eV}$ [30]. The electron energy scale calibration was performed in the premixed mixture of $\mathrm{CH}_{4}: \mathrm{N}_{2}: \mathrm{He} 1: 1: 1$ (established by absolute pressure measurement utilizing the capacitance gauge) in order to prevent the problems with different charging of the electrodes in different gases. Figure 2 shows the corresponding excitation functions for the $\mathrm{N}_{2}\left(\mathrm{C}^{3} \Pi_{\mathrm{u}} \rightarrow \mathrm{B}^{3} \Pi_{\mathrm{g}}\right)$ $(0,0)$, He I $\left(1 \mathrm{~s} 2 \mathrm{p}^{3} \mathrm{P}^{\mathrm{o}}{ }_{1,2}-1 \mathrm{~s} 4 \mathrm{~d}^{3} \mathrm{D}_{1,2,3}\right)$ and $\mathrm{CH}\left(\mathrm{A}^{2} \Delta \rightarrow \mathrm{X}^{2} \Pi\right)$ $(0,0)$ bands measured under the same experimental conditions. The excitation functions of $\mathrm{N}_{2}$ and $\mathrm{He}$ were then used to calibrate the electron energy scale. The agreement between energy scales calibrated by $\mathrm{N}_{2}$ and $\mathrm{He}$ was better than $0.015 \mathrm{eV}$. In addition, the $\mathrm{He}$ line has a stepwise cross section, where from the first derivative the same beam resolution was obtained as with the retarding potential method.

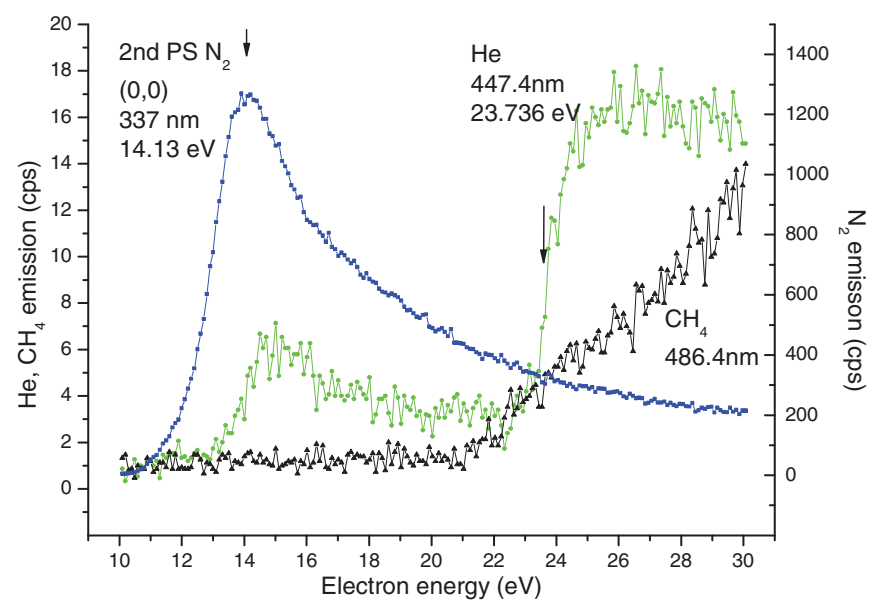

Figure 2. Excitation function of the $(0,0)$ band of the second positive system of $\mathrm{N}_{2}\left(\mathrm{C}^{3} \Pi_{\mathrm{u}} \rightarrow \mathrm{B}^{3} \Pi_{\mathrm{g}}\right)$ at $337 \mathrm{~nm}$ recorded as a function of the electron energy and in comparison with the $\mathrm{CH}\left(\mathrm{A}^{2} \Delta\right.$ $\left.\rightarrow X^{2} \Pi\right)(0,0)$ band and cross section for the He I $\left(1 \mathrm{~s} 2 \mathrm{p}^{3} \mathrm{P}^{\mathrm{o}}{ }_{1,2}-1 \mathrm{~s} 4 \mathrm{~d}\right.$ $\left.{ }^{3} \mathrm{D}_{1,2,3}\right)$ transition, measured at the same experimental conditions.

The data presented are raw data without any background subtraction or data manipulation. The arrows indicate the energy of the maximum in the emission cross section for $(0,0)$ transition of the second positive system $\mathrm{N}_{2}$ and the threshold for the excitation of the He excited state. The photon yield at $447.4 \mathrm{~nm}$ below the He onset arises from the $\mathrm{N}_{2}\left(\mathrm{C}^{3} \Pi_{\mathrm{u}} \rightarrow \mathrm{B}^{3} \Pi_{\mathrm{g}}\right)(6,8)$ transition.

Two different measurement modes were used in the present study, (i) fluorescence spectra were recorded at fixed electron energies and (ii) the electron energy dependence of a specific transition was measured by setting the optical monochromator to transmit the corresponding wavelength. Apparent thresholds in the electron energy scans were deduced utilizing a fitting routine based on an exponential power law [14]. The finite electron energy resolution was also taken into account. The energy uncertainty was deduced by the fitting procedure, as the fitting procedure includes the electron energy distribution function. If the data are of good quality (the statistical scatter data are low in comparison to the real 


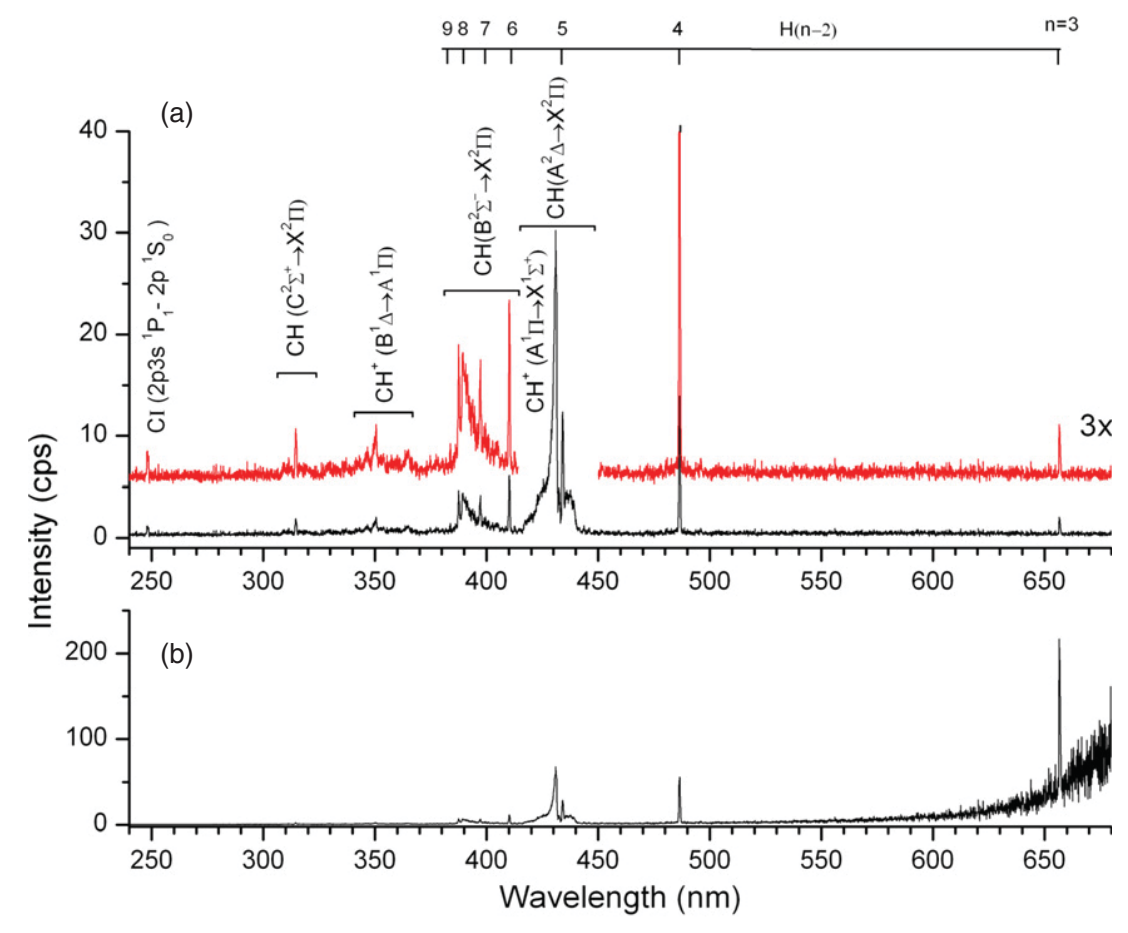

Figure 3. Emission spectrum of electronically excited species upon electron excitation (electron energy $=50 \mathrm{eV}$, optical monochromator slit $200 \mu \mathrm{m}$ ) of $\mathrm{CH}_{4}$. (a) Uncorrected spectrum, (b) spectrum corrected for the spectral sensitivity of the optical system.

structures in the data), it is possible to achieve uncertainties in the threshold energies better than the energy resolution of the electron beam (i.e., below $0.3 \mathrm{eV}$ ).

\section{Results and discussion}

Figure 3 shows the emission spectrum of electronically excited species upon electron excitation of $\mathrm{CH}_{4}$. The spectrum was recorded at the initial electron energy of $50 \mathrm{eV}$ covering the spectral range between 240 and $680 \mathrm{~nm}$. In the course of our study on electron excitation of methane, we observed emission signal (with photon frequency $v_{\mathrm{em}}$ ) from several electronically excited fragments within the spectral range of our optical monochromator:

$$
\begin{aligned}
\mathrm{e}^{-}+\mathrm{CH}_{4} & \rightarrow \mathrm{H}(n=3-9)+\ldots \rightarrow \mathrm{H}(n=2)+h v_{\mathrm{em}} \\
& \rightarrow \mathrm{CH}\left(\mathrm{A}^{2} \Delta\right)+\ldots \rightarrow \mathrm{CH}\left(\mathrm{X}^{2} \Pi\right)+h v_{\mathrm{em}} \\
& \rightarrow \mathrm{CH}\left(\mathrm{B}^{2} \Sigma^{-}\right)+\ldots \rightarrow \mathrm{CH}\left(\mathrm{X}^{2} \Pi\right)+h v_{\mathrm{em}} \\
& \rightarrow \mathrm{CH}\left(\mathrm{C}^{2} \Sigma^{+}\right)+\ldots \rightarrow \mathrm{CH}\left(\mathrm{X}^{2} \Pi\right)+h v_{\mathrm{em}} \\
& \rightarrow \mathrm{CH}^{+}\left(\mathrm{B}^{1} \Delta\right)+\ldots \rightarrow \mathrm{CH}^{+}\left(\mathrm{A}^{1} \Pi\right)+h v_{\mathrm{em}} \\
& \rightarrow \mathrm{CI}\left(3 \mathrm{~s}^{1} P^{\mathrm{o}}\right)+\ldots \rightarrow \mathrm{CI}\left(2 \mathrm{p}^{2}{ }^{1} \mathrm{~S}\right)+h v_{\mathrm{em}}
\end{aligned}
$$

In the emission spectrum, we also detected some additional weak bands such as the Douglas-Herzberg system $\mathrm{CH}^{+}(\mathrm{A}-\mathrm{X})$ at $\sim 422 \mathrm{~nm}$. However, due to the overlap with the stronger $\mathrm{CH}(\mathrm{A}-\mathrm{X})$ band, we were not able to separate this band in the present experiment for measurements of its excitation function. For the other atomic lines and molecular bands (1)-(6), we recorded photon yields as a function of the initial electron energy. We evaluated the curves and determined threshold energies for dissociative excitation channels.

\section{Fluorescence spectrum}

The electronic ground state of methane in $T_{\mathrm{d}}$ symmetry is ${ }^{1} \mathrm{~A}_{1}\left(1 \mathrm{a}_{1}\right)^{2}\left(2 \mathrm{a}_{1}\right)^{2}\left(1 \mathrm{t}_{2}\right)^{6}$ [31]. In agreement with all previous studies on electronic excitation of methane, photon emission from excited states of the methane molecule was not detected. Hence, the electronically excited states of methane are prone to dissociation into fragments, which are identified from the fluorescence spectrum shown in figure 3. The UV/VIS fluorescence spectrum is rich in atomic lines and molecular bands; the Balmer lines are easily identified in the spectrum as well as the emission bands of the $\mathrm{CH}\left(\mathrm{A}^{2} \Delta \rightarrow \mathrm{X}^{2} \Pi\right)$, $\mathrm{CH}\left(\mathrm{B}^{2} \Sigma^{-} \rightarrow \mathrm{X}^{2} \Pi\right), \mathrm{CH}\left(\mathrm{C}^{2} \Sigma^{+} \rightarrow \mathrm{X}^{2} \Pi\right)$. A third neutral fragment observed is atomic carbon $\mathrm{CI}\left(2 \mathrm{p} 3 \mathrm{~s}{ }^{1} \mathrm{P}^{\mathrm{o}}{ }_{1} \rightarrow 2 \mathrm{p}^{2}{ }^{1} \mathrm{~S}_{0}\right)$ at $247.9 \mathrm{~nm}$. Besides the neutral species, we are able to detect weak $\mathrm{CH}^{+}$emission bands like the Douglas-Herzberg system $\mathrm{CH}^{+}\left(\mathrm{A}^{1} \Pi \rightarrow \mathrm{X}^{1} \Sigma^{+}\right), \mathrm{CH}^{+}\left(\mathrm{B}^{1} \Delta \rightarrow \mathrm{X}^{1} \Sigma^{+}\right)$as well as $\mathrm{CH}^{+}\left(\mathrm{B}^{1} \Delta \rightarrow \mathrm{A}^{1} \Pi\right)$ transition.

Balmer series $-H(n \geqslant 3 \rightarrow 2)$. We focus now on the Balmer hydrogen series in methane. We were able to detect transitions as high as $n=9 \mathrm{H}_{\eta}(9-2 ; 383.7 \mathrm{~nm})$. We also observed a broad line at $\sim 364 \mathrm{~nm}$, where the Rydberg states of $\mathrm{H}$ are overlapped with $\mathrm{CH}\left(\mathrm{B}^{2} \Sigma \rightarrow \mathrm{X}^{2} \Pi\right)(1,0)$. We tried to resolve this part of spectra and to obtain excitation functions for $n>9$, however, 


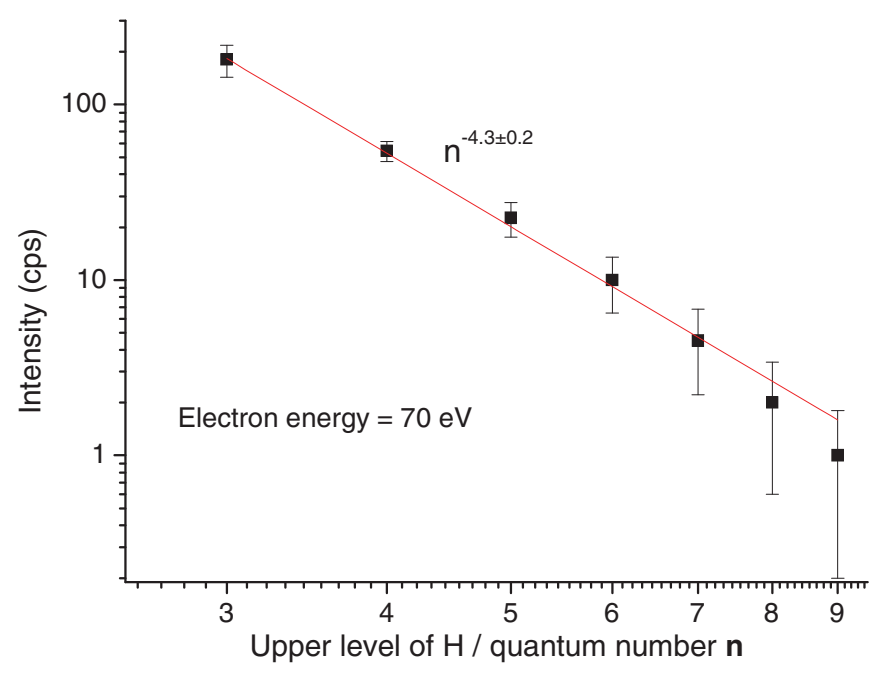

Figure 4. Double logarithmic plot of the photon yield of the Balmer lines (squares) versus the excitation state $n$. The best fit following an $n^{-4.3} \pm 0.2$ dependence is shown as a solid line (see the text). The intensities of the lines were corrected for spectral response of the system and derived from figure 3(b).

due to low intensity (high noise) and limited resolution of the optical monochromator, we did not succeed.

We note that in [32] absolute emission cross sections of the Balmer series $\mathrm{H}(3-2)$ up to $\mathrm{H}(11-2)$ for $100 \mathrm{eV}$ electrons impacting on methane were reported. The cross section scales strongly down with decreasing wavelength (for example, $\mathrm{H}(3-2) / \mathrm{H}(n \rightarrow 2)=556))$. It was suggested theoretically by Hartree that the intensities of atomic spectral lines of a given series are proportional to $\mathrm{n}^{-3}$ [32] and this dependence was expected as well for excitation cross sections of atoms and as well for molecules in high Rydberg states. Möhlmann and de Heer detected for several molecules (including $\mathrm{CH}_{4}$ ) that the intensities of Balmer lines follow $\mathrm{n}^{-5}$ dependence [32]. The deviation from the $\mathrm{n}^{-3}$ law was explained by contribution of autoionization states. They assumed that the high lying Rydberg states of the parent molecules are precursor states for the production of excited hydrogen. These Rydberg states are highly vibrationally excited (= super-excited states) [33] and lie energetically in the ionization continuum. Hence, the dissociative excitation is in competition with autoionization, which has higher probability the larger the $n$ is. Motohashi et al observed in their electron impact excitation experiments with methane an exponent of $4.5 \pm 0.2$ for the Balmer series [20] in agreement with [32]. In contrast, the exponential factors of the Balmer hydrogen series for dissociation of larger molecules like furan, tetrahydrofuran and isoxacole [34-36] yielded values much closer to the theoretical value (between 3.2 and 3.74). The dependence of the Balmer line intensities on $n$ as obtained in the present experiment is presented in figure 4. The Balmer line intensities $I$ are given in photon counts per seconds (cps) corrected for spectral response of the apparatus. As the spectrum was measured at constant electron current, the intensities are proportional to the excitation cross section. The systematic uncertainty of this cross section is wavelength dependent and we estimate an uncertainty of $20 \%$ in the wavelength range below $300 \mathrm{~nm}, 5-10 \%$ in the region between 300 and $500 \mathrm{~nm}$ and $20 \%$ above $500 \mathrm{~nm}$. The value of the exponent of $4.3 \pm 0.2$ derived here using leastsquares method fitting is in good agreement with the values previously determined by Möhlmann and de Heer [32] as well as Motohashi et al [20].

CH emission. As mentioned above the highest fluorescence signal from an excited molecular fragment is observed for $\mathrm{CH}$. In the present experiment, we can monitor three bands, $\mathrm{A}^{2} \Delta \rightarrow \mathrm{X}^{2} \Pi(0,0)(430.9 \mathrm{~nm}), \mathrm{B}^{2} \Sigma^{-} \rightarrow \mathrm{X}^{2} \Pi(0,0)(387.5 \mathrm{~nm})$ and $\mathrm{C}^{2} \Sigma^{+} \rightarrow \mathrm{X}^{2} \Pi(0,0)(314.5 \mathrm{~nm})$. The latter transition was reported in the previous electron impact excitation studies by Donohue et al [19] only. A closer look into the fluorescence spectrum (see figure 3) reveals clearly ro-vibrational structure of these $\mathrm{CH}$ bands. For example, figure 5(a) shows the $\mathrm{CH}(\mathrm{A}$ $\mathrm{X})$ system between 415 and $445 \mathrm{~nm}$ in detail recorded at higher resolution (70 $\mu \mathrm{m}$ slit of the optical monochromator). The simulation of this spectrum was carried out utilizing the LIFBASE program [37]. The photon yield in this range can be mainly ascribed to the $\mathrm{A}^{2} \Delta \rightarrow \mathrm{X}^{2} \Pi$ including $R, Q$ and $P$ branches of $0-0,1-1$ and 2-2 bands [38], superposed with the $\mathrm{H}(5-2)$ line at $434.2 \mathrm{~nm}$. Moreover, we were able to recognize in this spectral range of the measured spectrum weak structures resulting from the Douglas-Herzberg system $\mathrm{CH}^{+}\left(\mathrm{A}^{2} \Delta \rightarrow \mathrm{X}^{2} \Pi\right)$ at $\sim 422 \mathrm{~nm}$ and $\mathrm{CH}\left(\mathrm{B}^{2} \Sigma^{-} \rightarrow \mathrm{X}^{2} \Pi\right)(0,1)$ above $435 \mathrm{~nm}$ as well. Ro-vibrational structures were observed between 387 and $407 \mathrm{~nm}$ due to bands of $\mathrm{CH}\left(\mathrm{B}^{2} \Sigma^{-} \rightarrow \mathrm{X}^{2} \Pi\right)$ (0-0) transition (figure 5(b)) and between 362 and $367 \mathrm{~nm}$ due to branches of the $\mathrm{CH}\left(\mathrm{B}^{2} \Sigma^{-} \rightarrow \mathrm{X}^{2} \Pi\right)(1-0)$ band [21]. The line at $386.2 \mathrm{~nm}$ in figure 4 (b) could be assigned to the second order of the CI $\left(2 \mathrm{~s}^{2} 2 \mathrm{p}^{2}{ }^{1} \mathrm{D}_{2} \rightarrow 2 \mathrm{~s}^{2} 2 \mathrm{p} 3 \mathrm{~s}^{1} \mathrm{P}^{\circ}{ }_{1}\right)$ line at $193.1 \mathrm{~nm}$. This assignment is supported by the reduced width of this atomic line in comparison to the first order line, which we detected as well, however, is not depicted in the spectrum shown in figure 3 .

In view of the ro-vibrational analysis of the emission spectra of $\mathrm{CH}_{4}$, we mention the study by Kong et al [21] who used intense femtosecond laser pulses to excite and dissociate $\mathrm{CH}_{4}$ and measure fluorescence of excited fragments formed. Their fluorescence spectrum showed pronounced ro-vibrational emission spectra of the $\mathrm{CH}$ radical which indicated highly energized fragmentation products (termed as 'molecular explosion' in [21]). They deduced ro-vibrational temperatures from the ro-vibrational distribution representing a Boltzmann distribution and obtained temperatures between $1100 \pm 500 \mathrm{~K}\left(\mathrm{C}^{2} \Sigma^{+}\right.$state $)$and $2800 \pm 400 \mathrm{~K}\left(\mathrm{~A}^{2} \Delta\right)$. Ito et al [38] studied the internal energy distribution of the $\mathrm{CH}$ $\mathrm{A}^{2} \Delta$ state formed by electron impact dissociation of methyl halides and observed a vibrational temperature of $3300 \pm$ 400. It is also stated in [38] that similar temperatures can be obtained for small hydrocarbons like methane, acetylene and ethylene, which, however, was not confirmed later by Tokeshi et al using electron impact [39] and fast argon ion impact [40].

From the analysis of the present fluorescence spectrum, we may also quantitatively estimate the rotational and vibrational distributions of the $\mathrm{CH}$ excited states after electron impact. As mentioned above, we performed the simulation of the emission spectra utilizing the program LIFBASE [37]. 


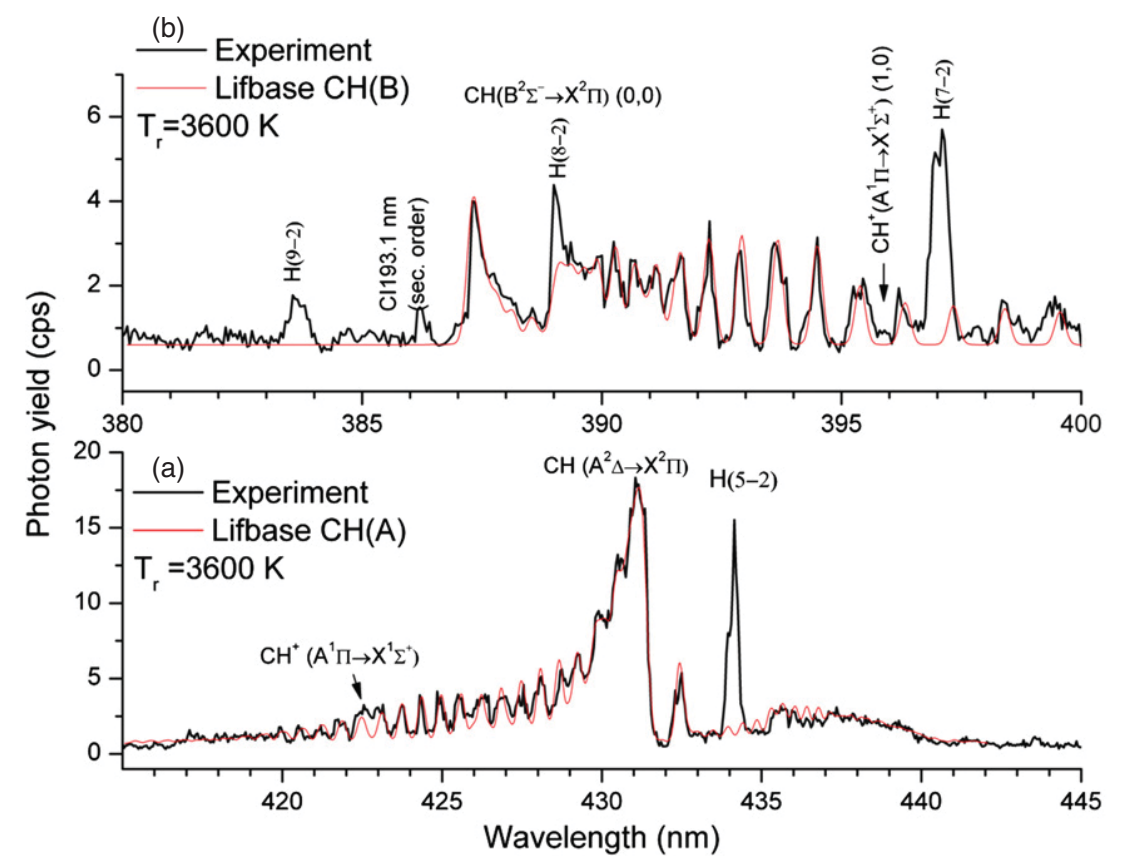

Figure 5. High-resolution emission spectra (electron energy $=50 \mathrm{eV}$, optical monochromator slit $70 \mu \mathrm{m}$ ) between (a) 415 and $445 \mathrm{~nm}$ and (b) 380 and $400 \mathrm{~nm}$. The experimental data are compared with calculated intensities using the LIFBASE program (see the text).

The best agreement between simulated and measured spectra was achieved (eyeball fitting) for $\mathrm{CH}(\mathrm{A})$ (figure 5(a)) using rotational temperature $T_{r}=3600 \pm 500 \mathrm{~K}$. In the simulation we have used the Voigt profile for the apparatus function, $0.25 \mathrm{~nm}$ FWHM (with 5\% Lorentzian contribution). The vibrational distribution of the $\mathrm{CH}(\mathrm{A})$ was non-thermal with $v=055.26 \%, v=118.22 \%, v=215.64 \%$ and $v=3$ $10.87 \%$. In the case of the $\mathrm{CH}(\mathrm{B})$, the simulated spectrum in figure 5(b) was generated for $v=0$ and $100 \%$ population of this vibrational state and the rotational distribution was as well characterized by the $T_{r}=3600 \pm 500 \mathrm{~K}$. We believe that the concept of temperature in the case of the fluorescence spectra may not be correct since the excitation-dissociation process of one molecule does not correspond to a thermodynamic equilibrium situation (Boltzmann distribution). Instead the amount of ro-vibrational excitation rather corresponds to the transition probabilities between the various states, i.e. the temperature depends on the Franck-Condon factors for the various transitions.

$\mathrm{CH}^{+}$emission. The present fluorescence spectrum also shows emission from ionic species which can be ascribed to $\mathrm{CH}^{+}$. Fluorescence of the latter ion was studied in detail previously [41], investigating the $\mathrm{C}^{+}-\mathrm{H}_{2}$ collision system. Donohue et al [19] reported bands corresponding to $\mathrm{CH}^{+}\left(\mathrm{B}^{1} \Delta \rightarrow \mathrm{A}^{1} \Pi\right)(350.3 \mathrm{~nm}), \mathrm{CH}^{+}\left(\mathrm{b}^{3} \Sigma \rightarrow \mathrm{a}^{3} \Pi\right)(348.7 \mathrm{~nm})$ and $\mathrm{CH}^{+}\left(\mathrm{A}^{1} \Pi \rightarrow \mathrm{X}^{1} \Sigma^{+}\right)(422.6 \mathrm{~nm})$ upon electron impact excitation of methane. The intensity of other vibrational transitions of the Douglas-Herzberg system $\left(\mathrm{A}^{1} \Pi \rightarrow \mathrm{X}^{1} \Sigma^{+}\right)$of the $\mathrm{CH}^{+}$ion [42], $((1-0)$ at $395.7 \mathrm{~nm}$ and $(2-0)$ at $374.5 \mathrm{~nm})$ are at the detection limit of the present technique, which is mainly limited by the low electron current and the dark count rate of the photomultiplier. In contrast to the $\mathrm{CH}^{+}\left(\mathrm{B}^{1} \Delta \rightarrow\right.$ $\left.\mathrm{A}^{1} \Pi\right)$ and $\mathrm{CH}^{+}\left(\mathrm{A}^{1} \Pi \rightarrow \mathrm{X}^{1} \Sigma^{+}\right)$, we do not see a clear indication of the $b^{3} \Sigma \rightarrow a^{3} \Pi$ transition: no peak is visible at $348.8 \mathrm{~nm}$ corresponding to the (0-0) band and moreover, we also do not observe the (1-1) band at $337 \mathrm{~nm}$ present in data of Harris et al [41]. In favour of an improved energy resolution, the present experiments were carried out with electron current several orders of magnitude lower in comparison to experiments with a simple electron gun. This is the most probable reason why some spectral features were not detected here, even when we increased the data acquisition time.

\section{Threshold energies}

In figure 6, we present as an example a selection of excitation functions for several emission lines and bands as a function of the electron energy. More excitation functions can be found in the supplementary material, available at stacks.iop.org/JPhysB/46/045203/mmedia. In tables 1 and 2 we list the corresponding thresholds for the Balmer hydrogen series and (hydro)carbon fragments, respectively. The present values are compared in these tables with threshold values reported in previous studies. For a few transitions investigated here $\left(\mathrm{H}_{\varepsilon}(7-2), \mathrm{H}_{\zeta}(8-2), \mathrm{H}_{\eta}(9-2), \mathrm{CH}\left(\mathrm{B}^{2} \Sigma^{-} \rightarrow \mathrm{X}^{2} \Pi\right)\right)$ no threshold values for electron impact can be found in the literature to the best of our knowledge. Threshold energies for a transition also give information on the molecular state involved. Bettega et al [43] calculated the lowest lying excited states of methane which are ${ }^{3} T_{2}$ states. The lowest state was found to be at $10.84 \mathrm{eV}$ (in very good agreement with Winstead et al [44] and Gil et al [45]). All electronically excited states of methane are dissociative [44]. For example, it was proposed that all states below $13 \mathrm{eV}$ will lead to the production of the neutral $\mathrm{CH}_{3}$ radical with a threshold energy of $7.5 \pm 0.3 \mathrm{eV}$ as determined by post-ionization of the fragment formed after dissociative excitation of $\mathrm{CH}_{4}$ [46]. 

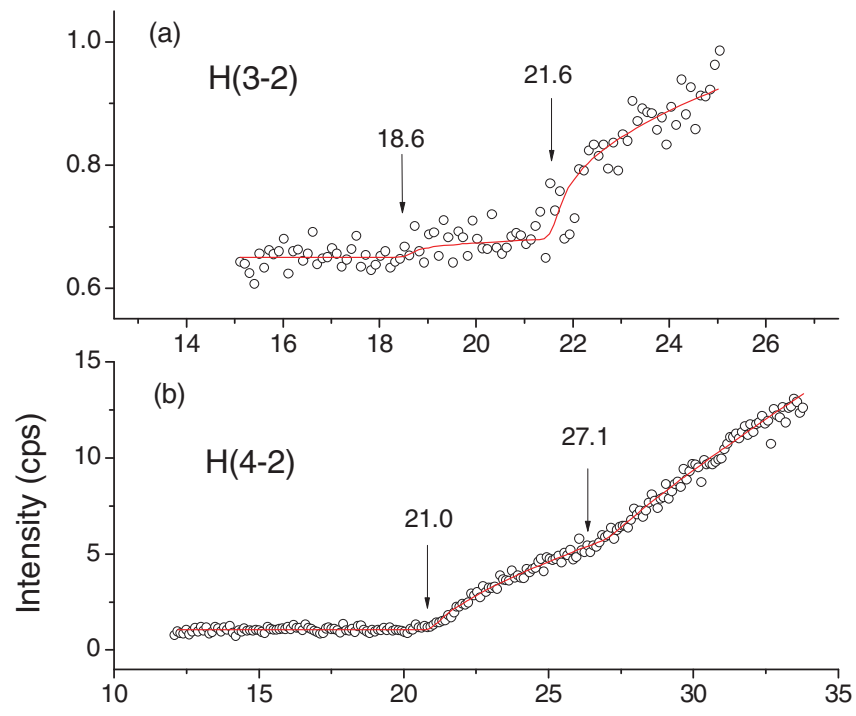

(c)

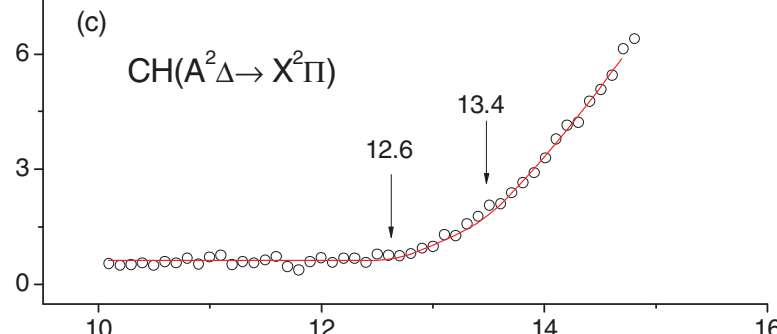

(d)
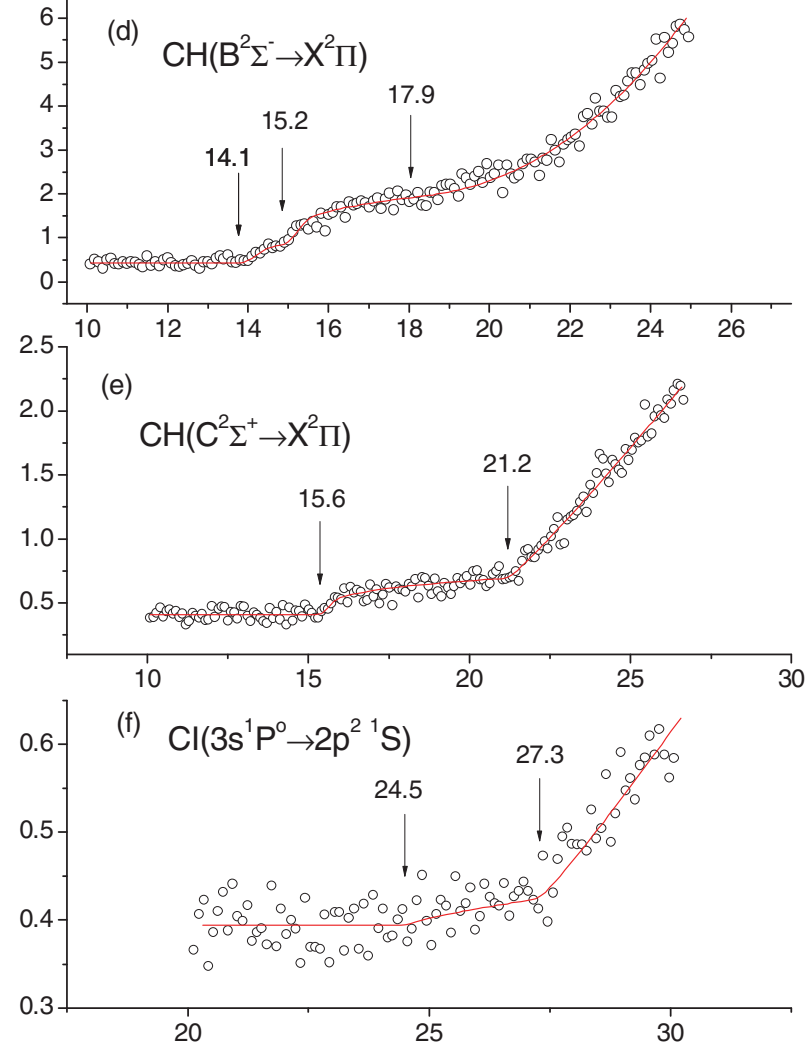

Electron energy (eV)

Figure 6. Photon yield of selected transitions measured as a function of the initial electron energy. Observed thresholds obtained using the fitting method in the measured energy range are indicated by arrows.

Table 1. Threshold energies for the Balmer series $(\mathrm{H}(n \geqslant 3 \rightarrow 2))$ obtained in the present experiment. The present values are compared with values calculated for selected reaction channels from thermochemical data [47] and with earlier experimental values.

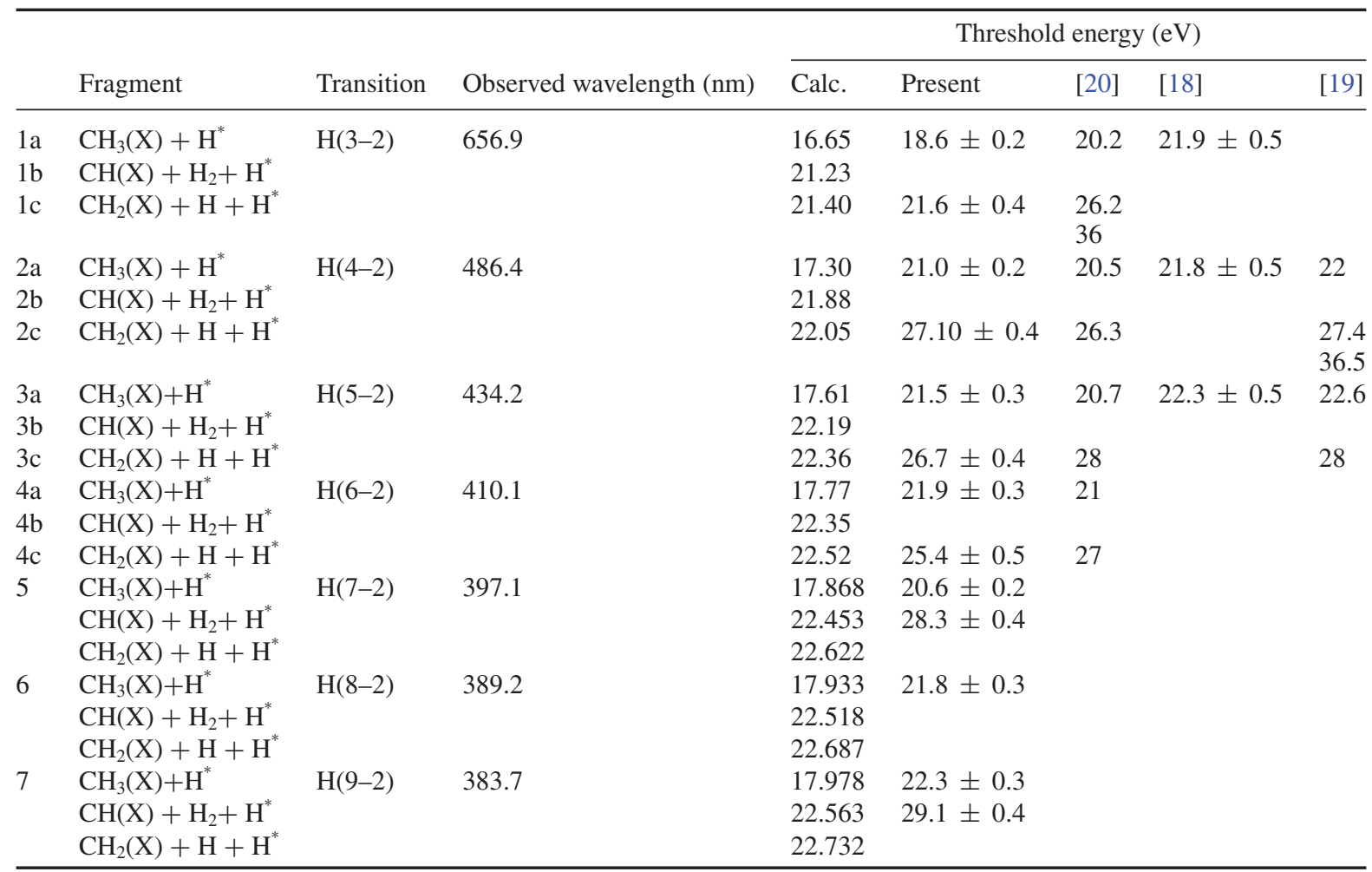


Table 2. Threshold energies for $\mathrm{CH}, \mathrm{CH}^{+}$and $\mathrm{CI}$ emission obtained in the present experiment. The present values are compared with values calculated for selected reaction channels from thermochemical data [47] and earlier experimental values.

\begin{tabular}{|c|c|c|c|c|c|c|c|c|}
\hline & \multirow[b]{2}{*}{ Fragment } & \multirow[b]{2}{*}{ Transition } & \multirow[b]{2}{*}{ Observed wavelength (nm) } & \multicolumn{5}{|c|}{ Threshold energy (eV) } \\
\hline & & & & Calc. & Present & [20] & [18] & [19] \\
\hline $8 \mathrm{a}$ & $\mathrm{CH}(\mathrm{A})+\mathrm{H}+\mathrm{H}_{2}$ & $\mathrm{~A}^{2} \Delta \rightarrow \mathrm{X}^{2} \Pi$ & 430.9 & 12.01 & $12.6 \pm 0.2$ & & & \\
\hline $8 \mathrm{~b}$ & $\mathrm{CH}(\mathrm{A})+3 \mathrm{H}$ & & & & $13.4 \pm 0.4$ & 14.2 & 14.6 & 13.4 \\
\hline $8 \mathrm{c}$ & $\mathrm{CH}(\mathrm{A})+\mathrm{H}_{2}+\mathrm{H}^{+}$ & & & 16.59 & $19.7 \pm 0.4$ & 20.4 & & \\
\hline \multirow[t]{2}{*}{$8 \mathrm{~d}$} & $\mathrm{CH}(\mathrm{A})+2 \mathrm{H}+\mathrm{H}^{+}$ & & & 25.8 & $22.4 \pm 0.4$ & & & 20.8 \\
\hline & & & & 30.2 & $32.5 \pm 0.4$ & 32.7 & & 35 \\
\hline $9 \mathrm{a}$ & $\mathrm{CH}(\mathrm{B})+\mathrm{H}+\mathrm{H}_{2}$ & $\mathrm{~B}^{2} \Sigma^{-} \rightarrow \mathrm{X}^{2} \Pi$ & 387.5 & 12.33 & $14.1 \pm 0.2$ & & & \\
\hline $9 \mathrm{~b}$ & $\mathrm{CH}(\mathrm{B})+3 \mathrm{H}$ & & & 16.91 & $15.2 \pm 0.4$ & & & \\
\hline $9 \mathrm{c}$ & $\mathrm{CH}(\mathrm{B})+2 \mathrm{H}+\mathrm{H}^{+}$ & & & 30.52 & $\begin{array}{l}17.9 \pm 0.4 \\
20.4 \pm 0.4\end{array}$ & & & \\
\hline $10 \mathrm{a}$ & $\mathrm{CH}(\mathrm{C})+\mathrm{H}+\mathrm{H}_{2}$ & $\mathrm{C}^{2} \Sigma^{+} \rightarrow \mathrm{X}^{2} \Pi$ & 314.5 & 13.08 & $15.6 \pm 0.2$ & & & 13.9 \\
\hline $10 \mathrm{~b}$ & $\mathrm{CH}(\mathrm{C})+3 \mathrm{H}$ & & & 17.66 & $21.2 \pm 0.4$ & & & $\begin{array}{l}20.8 \\
36\end{array}$ \\
\hline $11 \mathrm{a}$ & $\mathrm{CI}+2 \mathrm{H}_{2}$ & $3 \mathrm{~s}^{1} \mathrm{P}^{\mathrm{o}} \rightarrow 2 \mathrm{p}^{21} \mathrm{~S}$ & 247.9 & 13.2 & $\S$ & & & \\
\hline $11 \mathrm{~b}$ & $\mathrm{CI}+2 \mathrm{H}+\mathrm{H}_{2}$ & & & 17.72 & $\S$ & & & \\
\hline \multirow[t]{2}{*}{$11 \mathrm{c}$} & $\mathrm{CI}+4 \mathrm{H}$ & & & 22.24 & $24.5 \pm 0.6$ & & & $\begin{array}{l}24.8 \\
(26.2[17])\end{array}$ \\
\hline & & & & & $27.3 \pm 0.6$ & & & 28 \\
\hline \multirow[t]{2}{*}{12} & $\mathrm{CH}^{+}+\mathrm{H}+\mathrm{H}_{2}$ & $\mathrm{~B}^{1} \Delta \rightarrow \mathrm{A}^{1} \Pi$ & 350.2 & 26.25 & $28.4 \pm 0.4$ & & & 31.6 \\
\hline & $\mathrm{CH}^{+}+3 \mathrm{H}$ & & & 30.75 & $33.1 \pm 0.4$ & & & 34.9 \\
\hline
\end{tabular}

$\S$ Threshold likely not observable due to limited count rate.

The lowest onset observed here is below $13 \mathrm{eV}(12.6 \pm$ $0.2 \mathrm{eV}$ for $\mathrm{CH}\left(\mathrm{A}^{2} \Delta \rightarrow \mathrm{X}^{2} \Pi\right)$ ), i.e., in the overlap with the lowest excited states. However, it is evident that in this case no $\mathrm{CH}_{3}$ radical formation is associated with this process. Also superexcited states with excitation of two electrons of the target molecule may play a role as discussed in $[24,30]$ in detail. In the case of the $\mathrm{CH}\left(\mathrm{A}^{2} \Delta\right)$ fragment, we can see that the first threshold $(12.6 \pm 0.2 \mathrm{eV})$ approaches the calculated thermodynamic threshold for reaction $8 \mathrm{a}$ of $12.01 \mathrm{eV}$ (see table 2; formation of $\mathrm{H}_{\text {and }} \mathrm{H}_{2}$ ), and the second threshold with the reaction $8 \mathrm{~b}$ as calculated from the thermodynamic data found in [47] (see table I in the supplementary material, available at stacks.iop.org/JPhysB/46/045203/mmedia). In previous studies, the experimental threshold was detected $\sim 2 \mathrm{eV}$ above the thermodynamic threshold; in the present case, it is $0.6 \mathrm{eV}$. This difference would mean lower translational and ro-vibrational excitation of the products in the present experiment. However, we ascribe the difference in thresholds to result rather from the higher sensitivity of the present experimental setup. In the case of the excited states $\mathrm{CH}\left(\mathrm{B}^{2} \Sigma^{-}\right)$ and $\mathrm{CH}\left(\mathrm{C}^{2} \Sigma^{+}\right)$, the present experimental thresholds do not approach the theoretically predicted values so closely like in $\mathrm{CH}\left(\mathrm{A}^{2} \Delta\right)$. The difference between the dissociation limit and the thermodynamic threshold is released in the form of kinetic energies of fragments and in the internal ro-vibrational excitation of the products.

In [21], a picture of the dissociation dynamics of an initially excited methane molecule was drawn in the case of multi-photon excitation: after initial excitation a step-wise fragmentation process $\mathrm{CH}_{4} \rightarrow \mathrm{CH}_{2} \rightarrow \mathrm{CH}+\mathrm{H}$ was proposed by means of a simple analysis of the dissociation dynamics because the channels $\mathrm{CH}_{4} \rightarrow \mathrm{CH}+3 \mathrm{H}$ and $\mathrm{CH}_{4} \rightarrow \mathrm{CH}_{3} \rightarrow$ $\mathrm{CH}+2 \mathrm{H}$ would not lead to ro-vibrational excitation of $\mathrm{CH}$.
In the case of electron excitation, the ro-vibrational states of the $\mathrm{CH}$ fragment are not limited to stepwise fragmentation.

The dissociation limits calculated from the thermodynamic data for the dissociation reaction $\mathrm{CH}+$ $\mathrm{H}_{2}+\mathrm{H}$ of the other excited states of $\mathrm{CH}, \mathrm{B}^{2} \Sigma^{-}$and $\mathrm{C}^{2} \Sigma^{+}$, are shifted to slightly higher energies and can be found at 12.33 and $13.08 \mathrm{eV}$, respectively (see table 2). The limits for the channels with different dissociative products (8)-(11) are shifted accordingly. The lowest threshold for $\mathrm{CH}\left(\mathrm{B}^{2} \Sigma^{-}\right)$ observed in our measurement was $14.1 \pm 0.2 \mathrm{eV}$ and for the $\mathrm{CH}\left(\mathrm{C}^{2} \Sigma^{+}\right)$state $15.6 \pm 0.2 \mathrm{eV}$. In the case of $\mathrm{CH}\left(\mathrm{B}^{2} \Sigma^{-}\right)$ and $\mathrm{CH}\left(\mathrm{C}^{2} \Sigma^{+}\right)$, the dissociation channels $9 \mathrm{a}$ and $10 \mathrm{a}$ are accessible at the lowest threshold. Additional thresholds were obtained in $\mathrm{CH}\left(\mathrm{B}^{2} \Sigma^{-}\right)$and $\mathrm{CH}\left(\mathrm{C}^{2} \Sigma^{+}\right)$and correspond to the formation of three hydrogen atoms at $15.2 \pm 0.4$ and $21.2 \pm$ $0.4 \mathrm{eV}$, respectively. In the case of $\mathrm{CH}\left(\mathrm{B}^{2} \Sigma^{-}\right)$and $\mathrm{CH}\left(\mathrm{C}^{2} \Sigma^{+}\right)$ states, there most probably exists stronger energy partitioning in the products as it was in the case of the $\mathrm{CH}\left(\mathrm{A}^{2} \Delta\right)$ fragment.

We have also measured the excitation curves for Balmer lines up to $(n=9-2)$. In figure 6 the excitation curves of $\mathrm{H}(3-2)$ and $\mathrm{H}(4-2)$ are presented; excitation curves were also measured for the other Balmer lines up to $n=9$ (see figure I of supplementary material available at stacks.iop.org/JPhysB/46/045203/mmedia). We were not able to measure excitation functions for $n \geqslant 10$ due to limited resolution of the optical monochromator and the low intensity of the signal. The Balmer lines $\mathrm{H}(5-2)$ and $\mathrm{H}(8-2)$ were overlapping with $\mathrm{CH}$ emissions bands; however, we were able to account for the $\mathrm{CH}$ contributions in the data analysis. From the excitation function we determined the threshold for dissociative excitation into the Balmer series. The determined values are presented in table 1 . The present value for $\mathrm{H}(3-2)$ is shifted to a lower value (by almost $1.6 \mathrm{eV}$ in comparison to Motohashi et al [20]). On the other hand, 
the present $\mathrm{H}(4-2)$ value exceeds that of Motohashi et al by approximately $0.5 \mathrm{eV}$. The present experimental values for the first threshold are above the thermodynamic thresholds for the process:

$$
\mathrm{e}^{-}+\mathrm{CH}_{4} \rightarrow \mathrm{H}(n=3-9)+\mathrm{CH}_{3}+\mathrm{e}
$$

and below the threshold for the processes:

$$
\mathrm{e}^{-}+\mathrm{CH}_{4} \rightarrow \mathrm{CH}(\mathrm{X})+\mathrm{H}_{2}+\mathrm{H}^{*} \text {. }
$$

The thresholds listed in table 1 lead to the following conclusions: (i) a first onset below $20 \mathrm{eV}$ was observed only for $\mathrm{H}(3-2)$, all other Balmer lines have a threshold above $20.6 \mathrm{eV}$ still associated with reaction (7); (ii) a second onset is between 25.4 and $29.1 \mathrm{eV}$. Previously Motohashi et al measured threshold energies for the Balmer series from $\mathrm{H}(3-2)$ to $\mathrm{H}(6-2)$ and reported a (linear) threshold increase of about $0.2-0.3 \mathrm{eV}$ at each $n$ value [20]. In the present case, the value of the first threshold increases with $n$. A third threshold close to $36 \mathrm{eV}$, reported for two Balmer lines [19, 20], cannot be deduced in the present measurements. This may be described by a signal/noise ratio which prevents a clear signature of the threshold. Concerning the parent molecular state it was previously suggested that vibrationally excited Rydberg states formed at electron energies above $19.5 \mathrm{eV}$ (up to $24 \mathrm{eV}$ ) lead to dissociation into fragments including electronically excited hydrogen [20]. A list of calculated dissociation limits from thermodynamic data [47] for various combinations of fragments with excited hydrogen can be found in table 1 . The lowest dissociation limit is between $16.65(n=3)$ and $17.978 \mathrm{eV}(n=9)$ and corresponds to the products $\mathrm{H}+$ $\mathrm{CH}_{3}$. Dissociation reactions with simultaneous ion formation (e.g. $\mathrm{CH}_{3}{ }^{+}, \mathrm{CH}_{2}{ }^{+}$) can be ruled out within our investigated energy range because the thresholds observed are below the dissociation limit of these reactions [20].

The only fragment ion which shows fluorescence in the present measurements is $\mathrm{CH}^{+}$. The observed transition at $350.2 \mathrm{~nm}$ can be ascribed to the $\mathrm{B}^{1} \Delta \rightarrow \mathrm{A}^{1} \Pi$ and we deduce a strong threshold signal at $28.4 \pm 0.4 \mathrm{eV}$ and the second threshold at $33.1 \pm 0.4 \mathrm{eV}$ (see table 2). The first value is approximately $3.2 \mathrm{eV}$ lower than the first threshold of $31.6 \mathrm{eV}$ reported in [19]. The second threshold is shifted to lower energies by $1.8 \mathrm{eV}$ as well. Like for neutral $\mathrm{CH}$, in $\mathrm{CH}^{+}$the lowest dissociation limit implies formation of $\mathrm{H}_{2}+\mathrm{H}$ and has a thermodynamic value of $26.25 \mathrm{eV}$ [41]. In the case of the formation of $3 \mathrm{H}$, the threshold is increased by $4.5 \mathrm{eV}$ and is then above the experimental onset. It should be noted that we were not able to resolve the transitions $\mathrm{CH}^{+}\left(\mathrm{A}^{1} \Pi \rightarrow \mathrm{X}^{1} \Sigma^{+}\right)$ and $\mathrm{CH}^{+}\left(\mathrm{B}^{1} \Delta \rightarrow \mathrm{X}^{1} \Sigma^{+}\right)$due to their overlap with excited states of $\mathrm{CH}$ and thus we were not able to determine the thresholds.

For atomic carbon, we observed fluorescence for the transition CI $\left(3 \mathrm{~s}^{1} \mathrm{P}^{\mathrm{o}} \rightarrow 2 \mathrm{p}^{2}{ }^{1} \mathrm{~S}\right)$ at $247.9 \mathrm{~nm}$ which yields two onsets, the first one at $24.5 \pm 0.6 \mathrm{eV}$ and the second at 27.3 $\pm 0.6 \mathrm{eV}$ and energetically they could be assigned to the process $11 \mathrm{c}$ in table 2 ; however, we are not able to exclude processes $11 \mathrm{a}$ and $\mathrm{b}$ as well. These onsets are in reasonable agreement with values reported in [19] for this atomic state.

\section{Conclusion}

We have carried out a comprehensive study on electron impact excitation of $\mathrm{CH}_{4}$ utilizing an electron monochromator and detection system to monitor the photon emission of electronically excited species. In accordance with previous studies no emission of the excited parent molecule could be observed and we detected emission from the molecular $\left(\mathrm{CH}\right.$, and $\left.\mathrm{CH}^{+}\right)$and atomic (HI, CI) fragments. Subsequently, we have determined the corresponding threshold energies for the transitions detected. We also report threshold energies for five transitions not determined so far $\left(\mathrm{H}_{\varepsilon}(7-2), \mathrm{H}_{\zeta}(8-2)\right.$, $\left.\mathrm{H}_{\eta}(9-2), \mathrm{CH}\left(\mathrm{B}^{2} \Sigma^{-} \rightarrow \mathrm{X}^{2} \Pi\right)\right)$. For several excitation reactions, the present data yield threshold values different from former studies $\left(\mathrm{H}(3-2), \mathrm{CH}\left(\mathrm{A}^{2} \Delta \rightarrow \mathrm{X}^{2} \Pi(0,0), \ldots\right)\right.$, in most cases lower than in the former studies. We ascribe this to the improved resolution in the electron energy due to utilization of the electron monochromator as well as to good sensitivity and the high signal/noise ratio achieved in the present experimental system as well.

\section{Acknowledgments}

This work was supported by the Slovak Research and Development Agency, project nos APVV-0733-11 and DO7RP-0025-11, Slovak grant agency VEGA, project no 1/0379/11 and European Commission. JF acknowledges support from the COST Action CM0805 and the SNSF project no. PZ00P2-132357/1. JBM acknowledges support from the project of collaboration between Serbia and Slovakia 'Excitation and fragmentation of small biomolecules (2010 2011) and the MES RS (project no 171020). This work was supported by the European Commission under the Contracts of Association between EURATOM and the Comenius University as well as the Austrian Academy of Sciences. It was carried out within the framework of the European Fusion Development Agreement. The views and opinions expressed herein do not necessarily reflect those of the European Commission.

\section{References}

[1] Fuss M C, Muñoz A, Oller J C, Blanco F, Hubin-Franskin M-J, Almeida D, Limão-Vieira P and García G 2010 Chem. Phys. Lett. 486 110-5

[2] Shemansky D E, Stewart A I F, West R A, Esposito L W, Hallett J T and Liu X 2005 Science 308 978-82

[3] Huestis D L, Bougher S W, Fox J L, Galand M, Johnson R E, Moses J I and Pickering J C 2008 Space Sci. Rev. 139 63-105

[4] Ajello J M, Gustin J, Stewart I, Larsen K, Esposito L, Pryor W, McClintock W, Stevens M H, Malone C P and Dziczek D 2008 Geophys. Res. Lett. 35 L06102

[5] Stevens M H et al 2011 J. Geophys. Res. 116 A05304

[6] Lutz B L, Owen T and Cess R D 1976 Astrophys. J. $203541-51$

[7] Vuitton V, Yelle R V and McEwan M J 2007 Icarus $191722-42$

[8] Hesser J E and Lutz B L 1970 Astrophysical J. 159 703-18

[9] Fantz U, Meir S and the ASDEX Upgrade Team $2005 \mathrm{~J}$. Nucl. Mater. 337-339 1087-91 
[10] Nozaki T, Unno Y, Miyazaki Y and Okazaki K 2001 J. Phys. D: Appl. Phys. 342504

[11] Huber S E, Seebacher J, Kendl A and Reiter D 2011 Contrib. Plasma Phys. 51 931-43

[12] Reiter D and Janev R K 2010 Contrib. Plasma Phys. 50 986-1013

[13] Liu X and Shemansky D E 2006 J. Geophys. Res. 111 A04303

[14] Stano M, Matejcik S, Skalny J D and Märk T D 2003 J. Phys. B: At. Mol. Opt. Phys. 36 261-71

[15] Rawat P, Prabhudesai V S, Rahman M A, Ram N B and Krishakumar E 2008 Int. J. Mass Spect. 277 96-102

[16] Hoshino M, Matejcik S, Nunes Y, Ferreira da Silva F, Limao-Vieira P and Tanaka H 2011 Int. J. Mass Spect. 306 51-6

[17] Pang K D, Ajello J M, Franklin B and Shemansky D E 1987 J. Chem. Phys. 86 2750-64

[18] Aarts J F M, Beenakker C I M and De Heer F J 1971 Physica 53 32-44

[19] Donohue D E, Schiavone J A and Freund R S 1977 J. Chem. Phys. 67 769-80

[20] Motohashi K, Soshi H, Ukai M and Tsurubuchi S 1996 Chem. Phys. 213 369-84

[21] Kong F, Luo Q, Xu H, Sharifi M, Song D and Chin S L 2006 J. Chem. Phys. 125133320

[22] Wu C Y R and Judge D L 1981 J. Chem. Phys. 75 172-8

[23] Welch A R and Judge D L 1972 J. Chem. Phys. 57286

[24] Fukuzawa H, Odagiri T, Nakazato T, Murata M, Miyagi H and Kouchi N 2005 J. Phys. B: At. Mol. Opt. Phys. 38565

[25] Yachi K, Odagiri T, Ishikawa L, Nakazato T, Tsuchida T, Ohno N, Kitajima M and Kouchi N 2010 J. Phys. B: At. Mol. Opt. Phys. 43155208

[26] Országh J, Danko M, Ribar A and Matejcik S 2011 Nucl. Instrum. Methods B 279 76-9

[27] Matuska J, Kubala D and Matejcik S 2009 Meas. Sci. Technol. 20015901

[28] Stamatovic A and Schulz G J 1970 Rev. Sci. Instrum. 41423

[29] Zubek M 1994 J. Phys. B: At. Mol. Opt. Phys. 27 573-81

[30] Kramida A, Ralchenko Y, Reader J and NIST ASD Team 2012 NIST Atomic Spectra Database (ver. 5.0),
[Online] National Institute of Standards and Technology, Gaithersburg, MD (http://physics.nist.gov/asd, (date last accessed 24 October 2012)

[31] Kato M, Kameta K, Odagiri T, Kouchi N and Hatano Y 2002 J. Phys. B: At. Mol. Opt. Phys. 35 4383-400

[32] Möhlmann G R and de Heer F J 1979 Chem. Phys. 40 157-62 and references cited therein

[33] Nishikawa S and Watanabe T 1973 Chem. Phys. Lett. 22 590-4

[34] Wasowicz T J, Kivimäki A, Dampc M, Coreno M, de Simone M and Zubek M 2011 Phys. Rev. A 83033411

[35] Linert I, Lachowicz I, Wasowicz T J and Zubek M 2010 Chem. Phys. Lett. 498 27-31

[36] Dampc M and Zubek M 2008 Int. J. Mass Spectrom. 277 52-6

[37] Luque J and Crosley D R 1999 LIFBASE: Database and spectral simulation (version 1.5) SRI International Report MP 99-009

[38] Ito Y, Fujimaki A, Kobayashi K and Tokue I 1986 Chem. Phys. 105 417-22

[39] Tokeshi M, Nakashima K and Ogawa T 1996 Chem. Phys. $203257-66$

[40] Tokeshi M, Nakashima K and Ogawa T 1996 Chem. Phys. $206237-43$

[41] Harris H H, Crowley M G and Leventhal J J 1975 Phys. Rev. Lett. 34 67-70

[42] Hakalla R, Kepa R, Szajna W and Zachwieja M 2006 Eur. Phys. J. D 38481 and references therein

[43] Bettega M H F, Ferreira L G and Lima M A P 1998 Phys. Rev. A 574987

[44] Winstead C, Sun Q, McKoy V, Lino J L S and Lima M A P 1993 J. Chem. Phys. 982132

[45] Gil T J, Lengsfield B H, McCurdy C W and Rescigno T N 1994 Phys. Rev. A 492551

[46] Makochekanwa C, Oguri K, Suzuki R, Ishihara T, Hoshino M, Kimura M and Tanaka H 2006 Phys. Rev A 74042704

[47] NIST Chemistry webbook, NIST Standard Reference Database Number 69 (http://webbook.nist.gov/chemistry/) 